\title{
FIDEL ANTONIO ROIG SIMÓN
}

(1922-2009)

Mendoza fue lugar de paso, está en el camino a Chile que transitaron Tadeo Haenke, Miers, Otto Kuntze, entre otros, y donde residió John Gillies en Piedras de Afilar. La botánica autóctona se inició con Renato Sanzin, profesor de Patología Vegetal en la Escuela Enológica y de Botánica en el Colegio Nacional, que asesorado por C. Hicken comenzó sus herborizaciones en 1913. En 1916 su alumno Adrián Ruiz Leal coleccionó su primer ejemplar de herbario. Así surgió una línea continua que con Don Fidel Roig se expande abruptamente.

Don Fidel Antonio Roig nació en Mendoza el 16 de julio de 1922, junto con su hermano gemelo Arturo Andrés. Su padre, Fidel Roig Mattons, violinista y pintor catalán reconocido por

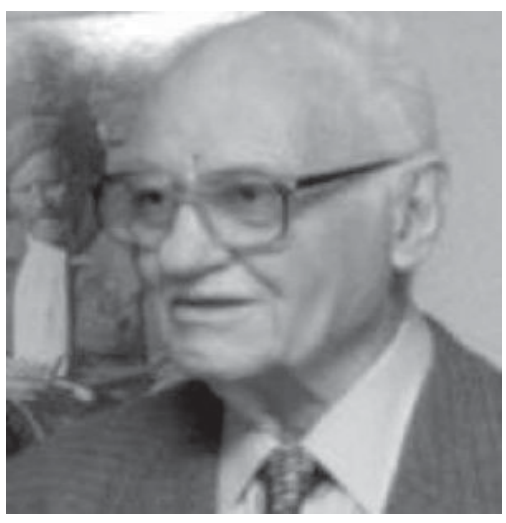
sus cuadros de la Cordillera, de su cruce por San Martín y de los Huarpes, tuvo cinco hijos: Fidel Antonio, botánico, Arturo Andrés, filósofo, Mario, Virgilio Germán, ecólogo y Enrique Franck, los que enriquecieron la vida cultural de su terruño.

Tempranamente desarrolló su vocación docente como maestro de grado, después en la enseñanza media y por último como Profesor Titular de Botánica Agrícola en la Facultad de Ciencias Agrarias de la Universidad Nacional de Cuyo, de la cual había egresado con el título de Ingeniero Agrónomo en 1952, y de la cual llegó ser su Decano en 1973.

Estuvo casado con Nuria Juñent, con quién tuvo tres hijos que son su continuidad, Fidel Alejandro es botánico y especialista en dendrocronología, Sergio es también Ingeniero Agrónomo y actual director del CRICYT, y Claudio es geólogo y trabaja en Ushuaia.

Con su hermano Virgilio contribuyó a la creación del Instituto Argentino de Investigaciones de Zonas Áridas (IADIZA).

Publicó 95 trabajos en revistas científicas, 14 libros y monografías, 41 capítulos en libros y dictó 33 conferencias ${ }^{1}$.

Publicó en revistas científicas de renombre y también en publicaciones y periódicos mendocinos, llevando a todo público los resultados de sus estudios sobre taxonomía, fitosociología, cartografía, fitogeografía, conservación, etnobotánica, arqueología, plantas medicinales y biodiversidad.

Su mayor aporte al desarrollo científico de su terruño es sin duda la formación de discípulos que hoy siguen sus pasos.

Nos conocimos en 1947 cuando nos iniciábamos en la Botánica, Don Fidel como Ayudante de la cátedra de Ruiz Leal y yo de paso a Santiago de Chile para estudiar las plantas de Philippi. Desde entonces hemos mantenido una relación de amistad, nutrida por su rica personalidad.

La Botánica argentina pierde uno de sus pilares y será recordado como tal.

Antonio Krapovickas

${ }^{1}$ La lista completa de su producción se publicó en el Boletín de la Sociedad Argentina de Botánica 43(3-4): 321-327. 2008. 